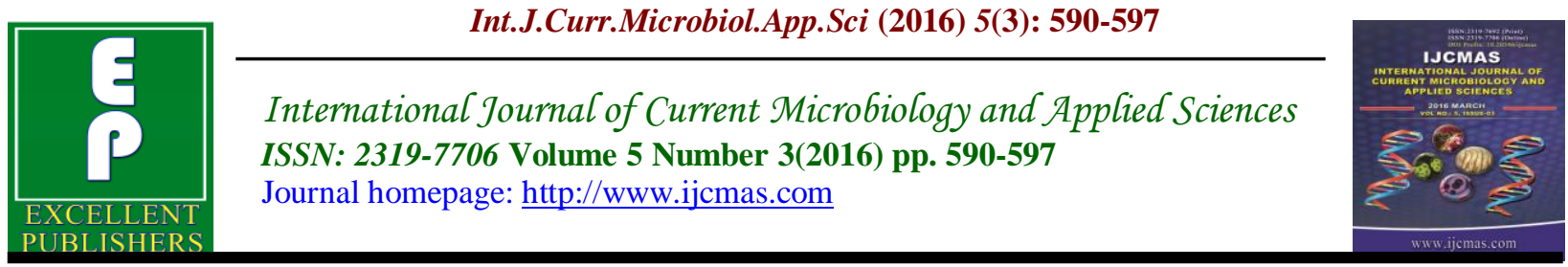

Original Research Article

http://dx.doi.org/10.20546/ijcmas.2016.503.068

\title{
Screening of In vitro Antioxidant Activity of Chloroform Extracts of Bryonopsis laciniosa Fruits
}

\author{
C.B. Sanjeevkumar, Ramesh L Londonkar*, Umesh Madire Kattegouda and \\ N. K. Asha Tukappa \\ Department of Biotechnology, Animal \& Pharmaceutical Biotechnology Laboratory, \\ Gulbarga University, Kalburgi, India \\ *Corresponding author
}

\section{A B S T R A C T}

\section{Keywords}

Bryonopsis laciniosa fruits, antioxidant assay, DPPH, ABTS, Hydrogen peroxide assay.

Article Info

Accepted:

18 February 2016

Available Online:

10, March 2016
Bryonopsis laciniosa is an annual climber with bright red fruits is a traditional plant used in India. The plant is used in treatment of broad range of diseases and disorders. In the present study, chloroform extract of $B$. laciniosa fruits were used to evaluate in vitro antioxidant study. Antioxidant assays like DPPH, ABTS, $\mathrm{H}_{2} \mathrm{O}_{2}$ and FRAP were used to measure the antioxidant capacity. Chloroform extract showed the effective antioxidant activity in all assays compared to ascorbic acid and BHT. The present study shows potential application of Bryonopsis laciniosa fruits suggesting their potential application as a health-promoting functional ingredient or natural preservative in foods.

\section{Introduction}

Reactive oxygen species (ROS) such as superoxide anion, hydroxyl radical and hydrogen peroxide are physiological metabolites formed during aerobic life as a result of the metabolism of oxygen. Although ROS at an extent is required for normal cell function but over accumulation of ROS results in oxidative stress, leading to damage of various biomolecules like proteins, DNA and lipids which is associated with chronic degenerative diseases, including cancer, coronary artery diseases, hypertension and diabetes etc. (Santharam et al., 2015 \& Gafrikova et al., 2014). In order to reduce the oxidative stress caused by various endogenous and exogenous free radicals, the human body has its own antioxidant defense mechanism against ROS. Antioxidants are synthesized within the body and can also be extracted from the food humans eat such as fruits, vegetables, seeds, nuts, meats and oil. These compounds react with free radicals and neutralize them (Raju 2005). There are two 
lines of antioxidant defence within the cell. The first line, found in the fat soluble cellular membrane consists of vitamin $E$, bcarotene and coenzyme Q; of these, vitamin $\mathrm{E}$ is considered the most potent chainbreaking antioxidant within the membrane of the cell. Inside the cell, water-soluble antioxidant scavengers are present (Marinal 2012). Antioxidants occurring naturally in leafy vegetables and seeds, such as ascorbic acid, vitamin $\mathrm{E}$ and phenolic compounds possess the ability to reduce the oxidative damage associated with many diseases. That is why many researchers have focused on natural antioxidants and, in the plant kingdom, numerous crude extracts and pure natural compounds have been reported to have antioxidant properties (Santharam et al., 2015).

A large number of medicinal plants has been investigated for their antioxidant properties. Natural antioxidants either in the form of raw extracts or their chemical constituents are very effective to prevent the destructive processes caused by oxidative stress (Zengin 2015 and Sayed 2012).

Bryonopsis laciniosa an annual climber of Cucurbitaceae family and one such plant species distributed throughout India. The fruit is expected to have antioxidant property as it is being used by the local communities for aphrodisiac, tonic. Sharp, cutting, lancinating or tearing pain, inflammation with muscular tension is cured by this plant (Malarvili. et al., 2015). Therefore to have the scientific validation on antioxidant properties, the fruits of this plant were taken for the present study. The chloroform extracts of B.laciniosa were used to investigate four different assays, DPPH scavenging activity, ABTS radicalscavenging capacity, Hydrogen peroxide scavenging $\left(\mathrm{H}_{2} \mathrm{O}_{2}\right)$ assay and the Ferric reducing-antioxidant power (FRAP) assay.

\section{Materials and Methods}

\section{Chemicals}

Chemicals, such as 1,1 diphenyl-2picrylhydrazyl (DPPH), 2,20-azino-bis(3ethylbenzothiazoline-6-sulphonic acid) diammonium salt (ABTS, 98\% purity), potassium ferricyanide, trichloroacetic acid (TCA), ferric chloride, and aluminium chloride, were purchased from Sigma Chemicals (Steinheim, Germany). Solvents such as methanol, chloroform and hexane were purchased from Merck (Germany). Butylated hydroxytoluene (BHT) and ascorbic acid were purchased from HiMedia (India). All chemicals and solvents used in the study were of analytical grade.

\section{Plant Material}

Fruits of $B$. laciniosa L plants $(5 \mathrm{~kg})$ were collected from the Gulbarga University campus during the month of December, 2013.

\section{Extract Preparation}

The collected fruits of $B$. laciniosa were washed under running tap water to remove dust particles and dried in the shade for $72 \mathrm{~h}$. The air-dried fruits were coarse powdered and stored in an air-tight dark glass bottle at $25{ }^{\circ} \mathrm{C}$ for further use. The powdered fruits $(100 \mathrm{~g})$ were successively extracted by three different solvents ( $350 \mathrm{~mL}$ each), from nonpolar to polar, i.e., hexane, chloroform and methanol, using Soxhlet extraction. The successive extracts of different solvents were dried, weighed and stored at $-4^{\circ} \mathrm{c}$ for further use.

\section{In vitro Antioxidant Activity}

The free radical scavenging activity of the 
chloroform extract was determined by using various in vitro assays such as DPPH, ABTS, Reducing power and Hydrogen peroxide assay.

\section{DPPH Radical Scavenging Activity}

The free radical scavenging activity using the 1.1- diphenyl-2-picryl- hydrazil (DPPH) reagent was determined according to Braca et al., 2002. The freshly prepared DPPH solution $(0.004 \%, \mathrm{w} / \mathrm{v})$ was dissolved in 95\% methanol. Different concentration of chloroform extract were mixed with DPPH solution $(900 \mu \mathrm{L})$. The reaction mixture was shaken well and incubated in the dark for 30 min at room temperature. Then the absorbance was taken at $517 \mathrm{~nm}$. Methanol (95\%), DPPH solution, ascorbic acid (AA) and BHT were used as a blank, a control and a reference standard, respectively. The scavenging activity was estimated based on the percentage of DPPH radical scavenged as the following equation:

DPPH radical scavenging activity $(\%)=(\mathrm{Ac}$ - As)/Ac × 100,

where $A c$ is the absorbance without the samples and As is the absorbance in the presence of the samples.

\section{ABTS Radical Scavenging Activity}

The 2,20-azinobis (3-ethylbenzthiazoline-6sulphonic acid), commonly called ABTS cation scavenging activity was performed by the method of Thoo et al. (2013) and Surveswaran et al. (2007) with a slight modification. Briefly, ABTS solution (7 $\mathrm{mM}$ ) was reacted with potassium persulfate $(2.45 \mathrm{mM})$ solution and kept for overnight in the dark to yield a dark coloured solution containing ABTS radical cations.

Prior to use in the assay $100 \mu \mathrm{L}$ of the ABTS solution with $3.9 \mathrm{~mL}$ of ethanol to obtain an absorbance of $0.700 \pm 0.02$ at $734 \mathrm{~nm}$ with temperature control set at $30^{\circ} \mathrm{C}$. Free radical scavenging activity was assessed by mixing Different concentrations of the chloroform extract $(1 \mathrm{~mL})$ were allowed to react with 1 $\mathrm{mL}$ of the ABTS solution, and the absorbance was measured at $734 \mathrm{~nm}$ after 6 min using a UV-visible spectrophotometer. Ascorbic acid and BHT were used standard reference for ABTS radical scavenging activity. The ABTS radical scavenging activity was calculated according to the following equation:

ABTS radical scavenging activity, $\%=(\mathrm{Ac}$ $-\mathrm{As}) / \mathrm{Ac} \times 100$,

where Ac is the absorbance without samples and As is the absorbance in the presence of the samples.

\section{Ferrous Reducing-Antioxidant Power (FRAP)}

The reducing powers of chloroform extracts were determined according to the methods of Oyaizu (1986) and Oh et al. (2013) with a slight modification. 0.25 of chloroform extracts of were added to Phosphate buffer $(0.25 \mathrm{ml}, 0.2 \mathrm{M}, \mathrm{pH} 6.6)$ and $1 \%$ potassium ferricyanide $(0.25 \mathrm{ml})$. The mixture was incubated at $50^{\circ} \mathrm{C}$ for $20 \mathrm{~min}$. Aliquots of trichloroacetic acid $(0.25 \mathrm{ml}, 10 \%)$ were added to the mixture, which was then centrifuged at $5000 \mathrm{rpm}$ for $5 \mathrm{~min}$. The upper layer of solution $(0.5 \mathrm{ml})$ was mixed with distilled water $(0.5 \mathrm{ml})$ and a freshly prepared ferric chloride solution $(0.1 \mathrm{ml}$, $0.1 \%)$. The absorbance was measured at 700 $\mathrm{nm}$. Increased absorbance of their action mixture indicated increased reducing power. The results were compared with Ascorbic acid and BHT as a standard reference; the readings were expressed as the mean absorbance value. 


\section{Hydrogen Peroxide-scavenging Activity}

The ability of the chloroform extract to scavenge hydrogen peroxide was determined by the method of Cetinkaya et al. (2012). Hydrogen peroxide solution $(1 \mathrm{mM})$ was prepared with $50 \mathrm{mM}$ phosphate buffer $(\mathrm{pH}$ 7.4). Different concentrations of the methanolic extract $(1 \mathrm{~mL})$ were allowed to react with $0.6 \mathrm{~mL}$ of the hydrogen peroxide solution. Absorbance was determined at 230 $\mathrm{nm}$ after 10 min against a blank solution containing phosphate buffer without hydrogen peroxide. The scavenging activity of chloroform extract was compared with Ascorbic acid and BHT. The hydrogen peroxide scavenging activity was calculated according to the following equation:

Hydrogen peroxide scavenging activity, $\%=$ $(\mathrm{Ac}-\mathrm{As}) / \mathrm{Ac}) \times 100$,

where Ac is the absorbance without the samples and As is the absorbance in the presence of the samples.

\section{Statistical Analysis}

All assays were carried out in triplicate, and the results were expressed as the mean \pm SD.

\section{Results and Discussion}

\section{Antioxidant Assays}

\section{DPPH Radical Scavenging Activity}

DPPH is a purple colored stable free radical, when reduced completely the colour changes from purple to colourless diphenylpicryl hydrazine. DPPH radicals react with suitable reducing agents and then electrons become paired-off and the solution loses colour stoichimetrically with the number of electrons taken up (Chidambara Murthy et al., 2003). The DPPH radical scavenging activity of chloroform extract were detected and compared with Ascorbic acid and BHT (Fig. 1). The antioxidant activity of the chloroform extract was $86.15 \%$ at the concentration of $1000 \mu \mathrm{g} / \mathrm{mL}$, and the radical scavenging activities of ascorbic acid and BHT at the same concentration were $99.05 \%$ and $95.27 \%$, respectively. Thus, the chloroform extract was effective in comparison with ascorbic acid and BHT. The $\mathrm{IC}_{50}$ values showed in Table 1 . were $251.8 \pm 0.60, \quad 31.66 \pm 2.3$ and $28.3 \pm 2.4$ $\mu \mathrm{g} / \mathrm{mL}$ for chloroform extract, ascorbic acid and BHT, respectively. Thus by comparing $\mathrm{IC}_{50}$ values of DPPH assay, BHT showed a effective antioxidant activity followed by ascorbic acid and methanolic extract. These overall results indicates that the methanolic extract has a proton-donating ability and can serve as a source of free radical inhibitors or scavengers possibly acting as primary antioxidants, along with the reference standards that have similar scavenging activities.

\section{ABTS Radical Scavenging Activity}

The decolorization of the $\mathrm{ABTS}^{+}$, through measuring the reduction of the radical cation as the percentage inhibition of absorbance at $734 \mathrm{~nm}$ (Re et al., 1999). $\mathrm{ABTS}^{+}$was generated by incubating $\mathrm{ABTS}^{+}$ chromophore through the reaction (Wolfenden et al., 1982). The presence of various chemical compounds in the chloroform extracts of B.laciniosa have inhibited the potassium persulfate activity and hence reduced the production of $\mathrm{ABTS}^{+}$. This study reports that the chloroform extracts of B.laciniosa has highest antioxidant activity $(90.45 \%$, $68.83 \%$ and $55.05 \%$, respectively) followed by ascorbic acid and BHT (Fig. 2). The $\mathrm{IC}_{50}$ values of the chloroform extract showed lower $\mathrm{IC}_{50}$ value $(310.6 \pm 0.94 \mu \mathrm{g} / \mathrm{mL})$ compared to ascorbic acid and BHT (507.6 
\pm 2.05 and $401 \pm 2.35 \mu \mathrm{g} / \mathrm{mL}$, respectively) clearly indicating chloroform extract acted as a potent antioxidant agent then standards.

\section{Hydrogen Peroxide Scavenging Activity}

Hydroxyl radical are the major active oxygen causing lipid peroxidation in enormous biological damage. The highly reactive hydroxyl radical can cause oxidative damage to DNA, lipid and protein (Srikanth G et al., 2010.)

The Hydroxyl radical scavenging activity of chloroform extract of were detected and compared with Ascorbic acid and BHT. The percentage inhibition at various concentration of as well as Ascorbic acid and BHT were calculated and plotted in Fig.
3. BHT showed the highest inhibition, followed by ascorbic acid and the methanolic extract $(96.57 \%, 94.05 \%$ and $77.46 \%$ respectively). When compared to IC50 values of both Ascorbic acid and BHT (73.66 \pm 0.94 and $66.6 \pm 0.9 \mu \mathrm{g} / \mathrm{mL}$, respectively), chloroform extracts (180 $\pm 1.41 \mu \mathrm{g} / \mathrm{mL}$ ) was as effective as both standards.

\section{Ferrous Reducing-Antioxidant Power (FRAP)}

A reducing power is an indicative of reducing agent having the availability of atoms which can donate electron and react with free radicals and then convert them into more stable metabolites and terminate the radical chain reaction (Ganu GP et al. 2010).

Table.1 IC50 values of DPPH, ABTS, Hydrogen Peroxide and Absorbance of Reducing Power of Chloroform Extract of B. Laciniosa Fruits

\begin{tabular}{|c|c|c|c|c|}
\hline Samples & $\begin{array}{c}\text { DPPH } \\
(\mu \mathrm{g} / \mathrm{mL})\end{array}$ & ABTS $(\mu \mathrm{g} / \mathrm{mL})$ & $\mathrm{H}_{2} \mathrm{O}_{2}(\mu \mathrm{g} / \mathrm{mL})$ & $\begin{array}{c}\text { Reducing power } \\
(\text { Abs at 700 } \mathrm{nm})\end{array}$ \\
\hline Chloroform Extract & $251.8 \pm 0.60$ & $310.6 \pm 0.94$ & $180 \pm 1.41$ & $0.827 \pm 0.02$ \\
\hline Ascorbic acid & $31.66 \pm 2.3$ & $507.6 \pm 2.05$ & $73.66 \pm 0.94$ & $1.33 \pm 1.24$ \\
\hline BHT & $28.3 \pm 2.4$ & $401 \pm 2.35$ & $66.6 \pm 0.9$ & $2.03 \pm 1.06$ \\
\hline
\end{tabular}

Results represented in means \pm standard deviation $(n=3)$

Figure.1 DPPH Radical Scavenging Activity of Chloroform Extract, Ascorbic Acid and BHT. Values are Means \pm SD $(n=3)$

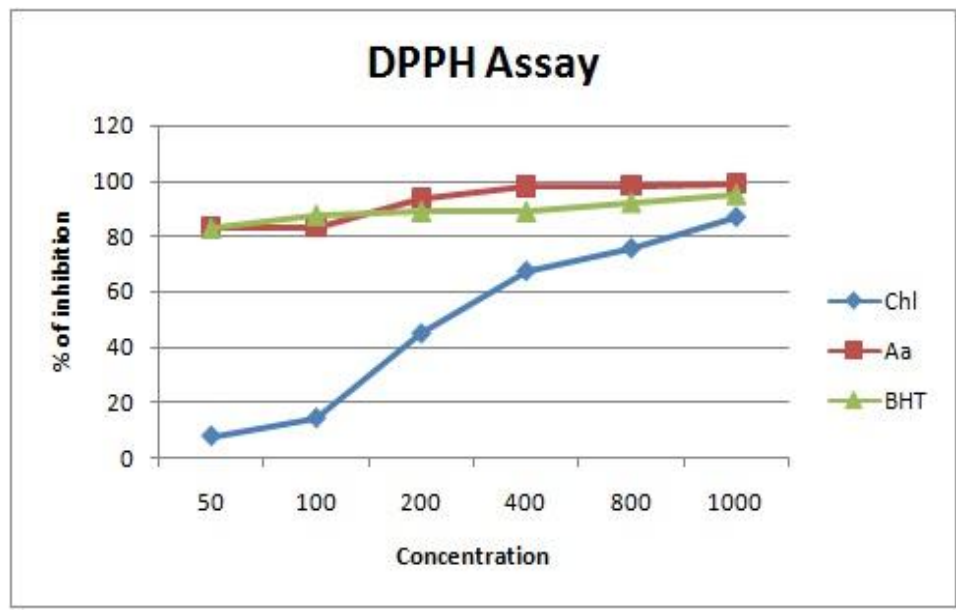


Figure.2 ABTS Radical Scavenging Activity of Chloroform Extract, Ascorbic Acid and BHT. Values are Means \pm SD $(n=3)$

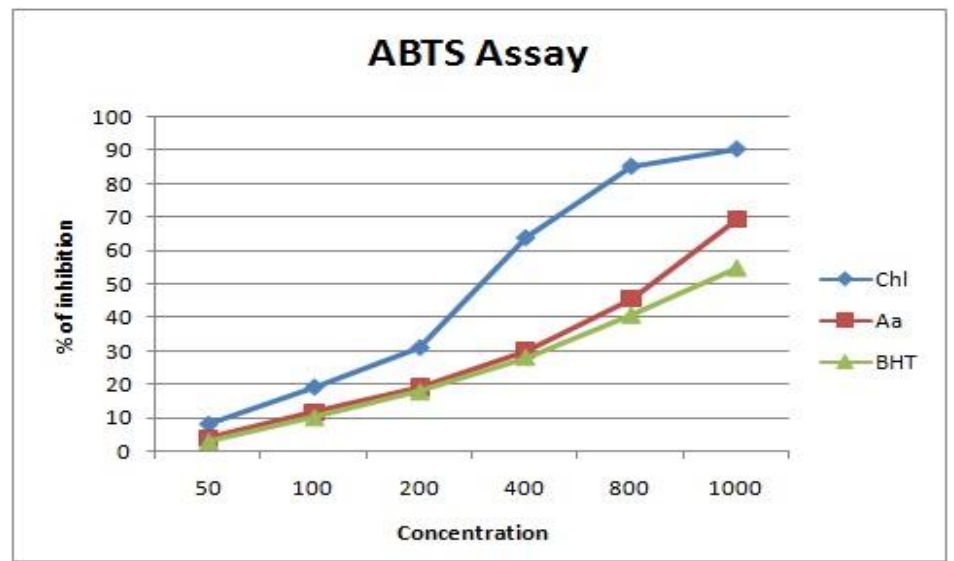

Figure.3 Hydroxyl Radical Scavenging Activity of Chloroform Extract, Ascorbic Acid and BHT. Values are Means \pm SD $(n=3)$

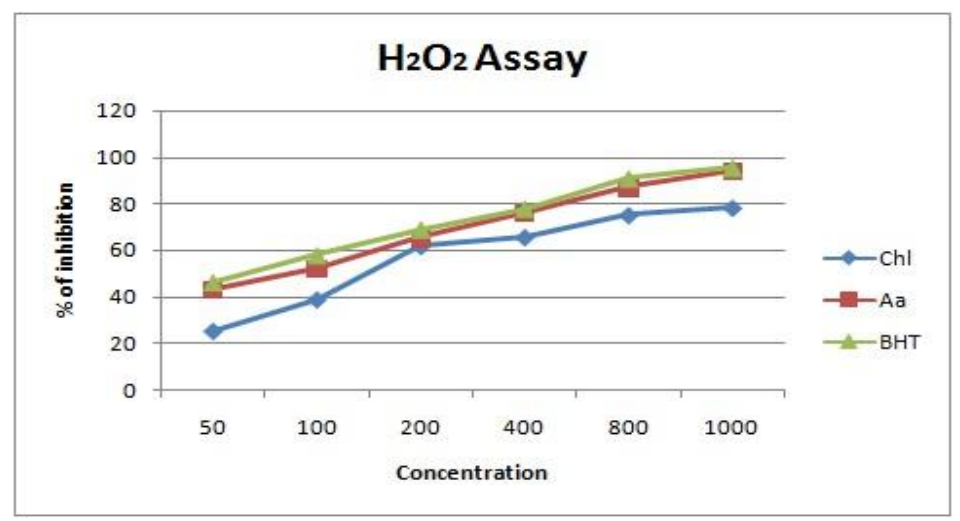

Figure.4 Reducing Power of Chloroform Extract, Ascorbic Acid and BHT Values are Means \pm SD $(n=3)$

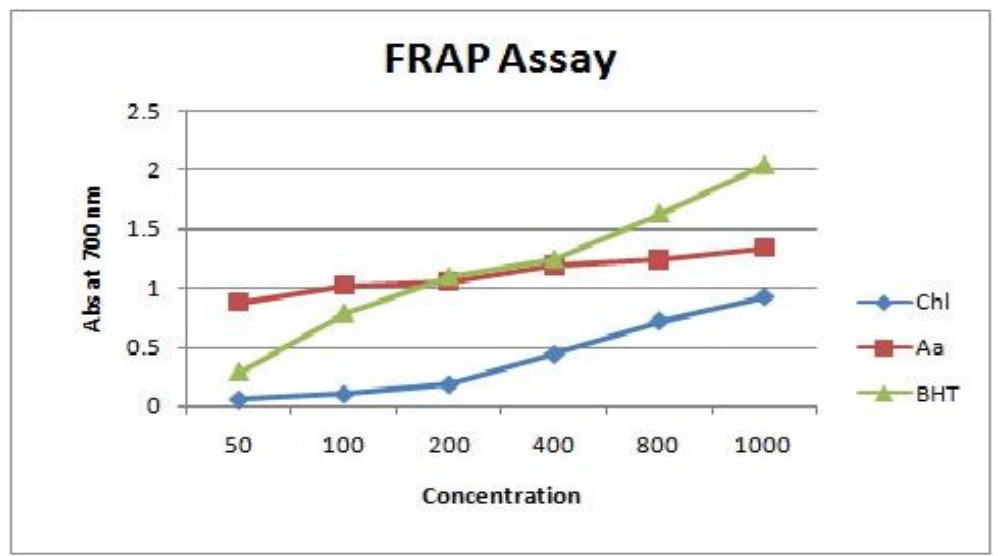


The antioxidant activity of the chloroform extract was investigated, along with ascorbic acid and BHT as standard references. The reducing power of the $B$. laciniosa extract as well as that of ascorbic acid and BHT is shown in Fig. 4. BHT showed higher reducing power $(2.03 \pm 0.06)$ than ascorbic acid $(1.33 \pm 0.04)$ and the chloroform extract (0.921 \pm 0.06$)$. Accordingly, chloroform extract of B.laciniosa might contain a sizable amount of reductants which may react with the free radicals to stabilize and terminate from free radical chain reaction.

In conclusion, the overall assay concludes that the chloroform extract of B.laciniosa fruits showed strong antioxidant activity when compared to standards such as ascorbic acid and BHT. Presence of phenol and other compounds may account for this fact. So these findings of present study suggest that this plant have a potential source of natural antioxidant. Further studies are warranted for the isolation and characterization of antioxidant compounds, and also in vivo studies are needed for understanding their mechanism of action as antioxidants.

\section{References}

Braca, A., Sortino, C. and Politi, M. 2002. Antioxidant activity of flavonoids from Licania licaniae flora. J Ethnopharmacol 79: 379-381.

Cetinkaya, Y., Gocer, H., Menzek, A. and Gulcin, I. 2012. Synthesis and antioxidant properties of $(3,4$ dihydroxyphenyl) $(2,3,4-$

trihydroxyphenyl) methanone and its derivatives. Archiv der Pharmazie 345:323-334.

Chidambara Murthy, K.N., Vanitha, A., Mahadeva Swamy, M. and Ravishankar, G.A. 2003. Antioxidant and Antimicrobial Activity of Cissus quadrangularis L. J Med Food, 6(2): 99-105.

Gafrikova, M., Galova, E., and Sevcovicova A. 2014. Extract from Armoracia rusticana and its flavonoid components protect human lymphocytes against oxidative damage induced by hydrogen peroxide. Molecules.19(3):3160-3172.

Ganu, G.P., Jadhav S.S. and Deshpande A.D. 2010. Antioxidant and antihyperglycemic potential of methanolic extract of bark of Mimusops elengi $\mathrm{L}$ in mice. Res $\mathrm{J}$ Pharm Biol Chem Sci, 1:67-77.

Malarvili Thekkumalai, Ramya Bashyam and Velavan Sivanandham. 2015. Evaluation of Phytoconstituents of Bryonopsis laciniosa fruit by UVVisible Spectroscopy and FTIR analysis. Pharmacognosy Journal Vol: 7 Issue: 3 Pages: 165-170

Marinal, S. and Viji Stella Boi G. In vitro antioxidant activity and total phenolic content of leaf extracts of Limonia crenulata (Roxb). J Nat Prod Plant Resour. 2012; 2(1):209214.

Oh Jungmin, Heonjoo Jo, Ah Reum Cho, Sung-Jin Kim and Jaejoon Han. 2013. Antioxidant and antimicrobial activities of various leafy herbal teas. FOOD CHEM 31, 403-409.

Oyaizu, M. 1986. Studies of products of browning reaction: antioxidative activities of products of browning reaction prepared from glucosamine. Jpn J Nutr, 44(6), 307-315.

Raju S.M and Nageshwara Rao J.S. 2005. Jaypee's review of medical biochemistry. New Delhi: Jaypee Brothers Publishers. Chapter 7, Vitamins; p. 65-87.

Roberta Re. Nicoletta Pellegrini. Anna Proteggente. Ananth Pannala. Min Yang and Catherine Rice-Evans. 1999. Antioxidant activity applying an 
improved ABTS Radical cation decolorization assay. Free Radic. Biol. Med, 26: 1231-1237.

Santharam, E., Ganesh, P. and Soranam, R. 2015. Evaluation of in vitro free radical scavenging potential of various extracts of whole plant of Calycopteris floribunda (Lam). J Chem Pharm Res.7(1):860-864.

Sayed, N., Khan, M.R. and Shabbir, M. 2012. Antioxidant activity, total phenolic total and flavonoid contents of whole plant extracts Torilis leptophylla L. BMC Complement Altern Med. 12:112.

Srikanth, G., Babu, S.M., Kavitha, C.H.N., Roa, M.E.B., Vijaykumar, N. and Pradeep, C.H. 2010. Studies on in vitro antioxidant activities of Carica papaya aqueous leaf extract. Res $\mathbf{J}$ Pharm Biol Chem Sci, 1:59-65.

Surveswaran, S., Cai, Y.Z., Corke, H. and Sun, M. 2007. Systematic evaluation of natural phenolic antioxidants from 133 Indian medicinal plants. FOOD
CHEM, 102(3), 938-953.

Thoo Yin Yin, Faridah Abas, Oi-Ming Lai, Chun Wai Ho, Jie Yin, Rikke V. Hedegaard, Leif H. Skibsted and Chin Ping Tan. 2013. Antioxidant synergism between ethanolic Centella asiatica extracts and a-tocopherol in model systems. FOOD CHEM 138, 1215-1219.

Wolfenden, B.S. and Willson, R.L. 1982. Radical-cations as reference chromogens in kinetic studies of oneelectron transfer reactions: pulse radiolysis studies of [2,2-azinobis-(3ethylbenzthiazoline-6-sulphonate)] J. Chem. Soc. Perkin Trans, 2: 805-812.

Zengin, G., Cakmak, Y.S., and Guler G.O. 2011. Antioxidant properties of methanolic extract and fatty acid composition of Centaurea urvillei DC. subsp. hayekiana Wagenitz. Rec Nat Prod. 5:123-132.

\section{How to cite this article:}

Sanjeevkumar, C.B., Ramesh L Londonkar, Umesh Madire Kattegouda and N. K. Asha Tukappa. 2016. Screening of In vitro Antioxidant Activity of Chloroform Extracts of Bryonopsis laciniosa Fruits. Int.J.Curr.Microbiol.App.Sci. 5(3): 590-597. doi: http://dx.doi.org/10.20546/ijcmas.2016.503.068 